\title{
Phalloplasty: understanding the chaos
}

\author{
Megan Lane ${ }^{1}$, Emily C. Sluiter ${ }^{1}$, Shane D. Morrison², Devin Coon ${ }^{3}$, Katherine M. Gast ${ }^{4}$, Jens U. Berli ${ }^{5}$, \\ William M. Kuzon ${ }^{1}$ \\ 'Section of Plastic Surgery, University of Michigan, Ann Arbor, MI 48109, USA. \\ ${ }^{2}$ Division of Plastic Surgery, University of Washington School of Medicine, Seattle, WA 98195, USA. \\ ${ }^{3}$ Department of Plastic and Reconstructive Surgery, Johns Hopkins University School of Medicine, Baltimore, MD 21205, USA. \\ ${ }^{4}$ Division of Plastic Surgery, University of Wisconsin, Madison, WI 53792, USA. \\ ${ }^{5}$ Division of Plastic and Reconstructive Surgery, Oregon Health and Science University, Portland, OR 97239, USA.
}

Correspondence to: Dr. William M. Kuzon, Section of Plastic Surgery, Michigan Medicine, 1500 E. Medical Center Drive, 2130 Taubman Center, SPC 5340,Ann Arbor, MI 48109, USA. E-mail: wkuzon@med.umich.edu

How to cite this article: Lane M, Sluiter EC, Morrison SD, Coon D, Gast KM, Berli JU, Kuzon WM. Phalloplasty: understanding the chaos. Plast Aesthet Res 2020;7:51. http://dx.doi.org/10.20517/2347-9264.2020.106

Received: 11 May 2020 First Decision: 2 Jun 2020 Revised: 20 Jun 2020 Accepted: 4 Aug 2020 Published: 27 Sep 2020

Academic Editor: Marlon E. Buncamper Copy Editor: Cai-Hong Wang Production Editor: Jing Yu

\begin{abstract}
Wide variation in overall strategies and surgical specifics for masculinizing genital surgery has created a "phalloplasty chaos" that is confusing to both surgeons and patients seeking gender confirming surgery. The purpose of this article is to review masculinizing genital confirming surgery, or "phalloplasty", focusing on specific goals and categorizing each component of the surgical process. Experienced surgeons from several highvolume centers review and categorize the commonly employed strategies and techniques for gender confirming phalloplasty, including the permutations of approaches to cutaneous flap for phallic construction, the sequence and staging of procedures, and strategies for urethral construction. There is no clear advantage or reduction in complications associated with particular sequences of urethral and phallic reconstruction. Because no single technique or staging strategy has proven superior for gender confirming genital surgery, it is paramount that surgeons are knowledgeable of all available options and the associated advantages, disadvantages, and risks.
\end{abstract}

Keywords: Transgender, phalloplasty, FtM, gender dysphoria, gender reassignment, transmasculine, gender confirmation surgery, gender confirming surgery, gender affirming surgery, transgender genital surgery

\section{INTRODUCTION}

The purpose of this article is to review masculinizing genital gender confirming surgery (GCS) or "phalloplasty". Experienced surgeons from several high-volume centers review and categorize the

\footnotetext{
(c) () T) The Author(s) 2020. Open Access This article is licensed under a Creative Commons Attribution 4.0 International License (https://creativecommons.org/licenses/by/4.0/), which permits unrestricted use, sharing, adaptation, distribution and reproduction in any medium or format, for any purpose, even commercially, as long as you give appropriate credit to the original author(s) and the source, provide a link to the Creative Commons license, and indicate if changes were made.
}

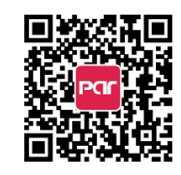




\section{Reproductive}

organs

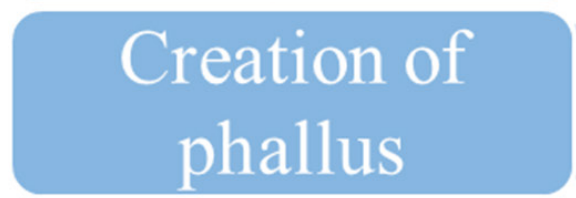

voiding

sensation

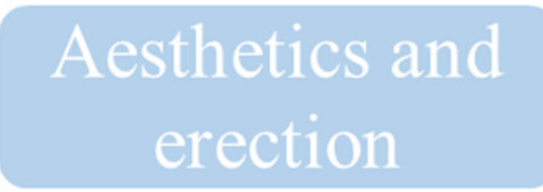

-Hysterectomy

- Salphingoopherectomy

-Vaginectomy

\section{$\cdot$ RFFF}

-ALT

- Other
-Pars fixa reconstruction

- Creation of pars pendulans
-Preservation of at least one dorsal clitoral nerve at the base

- Coaptation of cutaneous nerve branch in chosen flap

Figure 1. Goals of phalloplasty and procedures to create a masculine phallus. As discussed throughout the paper, there are countless combinations of procedures that can be offered to patients on the basis of their specific goals and preferences in addition to chronologic order. Depicted are the core procedures involved in genital masculinization. RFFF: radial forearm free flap; ALT: anterolateral thigh

commonly employed strategies and techniques for gender confirming phalloplasty, focusing on specific goals and categorizing each component of the surgical process. There is wide variation among centers in the choice of cutaneous flap for phallic construction, the sequence and staging of procedures, and in particular, the strategies for urethral construction. All centers performing masculinizing genital GCS should ideally employ a consistent, local algorithm tailored to the available expertise of the participating surgeons while also allowing for appropriate patient preference.

\section{MASCULINIZING GENITAL GCS: INDICATIONS AND PATIENT SELECTION}

In appropriately selected patients, GCS has been clearly demonstrated to improve body image ${ }^{[1]}$, psychosexual functioning ${ }^{[2]}$, and other quality of life measures ${ }^{[3]}$ as well as reducing or eliminating gender dysphoria ${ }^{[4]}$. For transgender or non-binary patients who were assigned female at birth and who possess female genital anatomy, construction of a male penis and scrotum to affirm their male gender has been generically termed phalloplasty. However, the transformation of vulvar to penile genitalia is a complex surgical challenge requiring multiple staged procedures; Figure 1 lists a typical sequence of procedures. The propagation of misinformation and unrealistic expectations in the patient population has compounded this "phalloplasty chaos".

The primary indication for any GCS is to relieve the individual's gender dysphoria by aligning their anatomy with their gender identity. Two things should be emphasized relative to that statement. First, human gender identity is complex. Although a majority of individuals identify as cis-gender male or cis-gender female, the spectrum of gender identity is broad, and the recent proliferation of descriptive terminology is still inadequate to describe many individuals' internal sense of their gender. Therefore, masculinizing genital GCS should not be viewed as a cookie-cutter process to construct anatomically 
analogous male genitalia for all patients. Each patient's surgical plan should be tailored to best confirm the individual's gender identity and to the individual's willingness to undergo staged procedures and to accept surgical risk, with the latter varying depending on preexisting comorbidities. This may mean that for a given patient the components of phalloplasty discussed below will vary, most commonly by omitting certain elements of a full transformation. This variability, of course, adds to the chaos.

Secondly, we recognize and understand that while the use of gender dysphoria as a diagnosis has helped many transgender patients gain access to medically necessary care, stating that the indication for GCS is to "treat" that diagnosis, and even the notion that surgery must have an indication and must "treat something" with direct benefit to the patient, has been criticized as "pathologizing" to non-cis identified individuals ${ }^{[5]}$. While acknowledging this debate, we emphasize the demonstrated health benefits of medically necessary GCS when applied appropriately ${ }^{[4,6,7]}$. As for any surgery, the indications for intervention and the proper selection of patients are critical to achieving these successful outcomes. Because surgeons alone do not have the expertise to determine which patients will see relief of gender dysphoria through surgical intervention, multidisciplinary collaboration is critical for patient selection. The World Professional Association for Transgender Health Standards of Care (WPATH SOC) has been criticized as pathologizing, paternalistic and authoritative "gatekeeping" ${ }^{[8-10]}$. Although the WPATH SOC may sometimes be applied in this manner, that is not the intent. Rather, the SOC should not be viewed as a set of rigid rules, but instead viewed as a statement of principles to structure communication among the multidisciplinary team working to achieve the best outcome for each patient. The overarching goal is to prevent patient harm through inappropriate intervention. As a result, we advocate adherence to the WPATH SOC when selecting patients for masculinizing GCS. Again, we acknowledge that this is not a universally held opinion.

\section{GOALS OF MASCULINIZING GCS}

Once patients have been identified as a surgical candidate, their individual goals, tolerance for surgical risk, and their willingness to engage in multiple staged procedures will guide surgical planning. The general goals of masculinizing genital GCS include: (1) the preservation of erogenous and orgasmic sensation; (2) the anatomic transformation of the vulva and vagina to a penis and a scrotum; (3) achieving an appropriately directed urinary stream, including standing urination if the patient so desires; (4) achieving sensation in the neophallus; and (5) providing for erectile potential sufficient for penetrative intercourse. Of these goals, the preservation of erogenous and orgasmic potential is most important and, because preservation of an innervated clitoris at the base of the neophallus will preserve erogenous/orgasmic sensation in nearly all patients, is associated with the least variance in strategic approach from center to center ${ }^{[11]}$. The remaining goals will achieve varying significance for individual patients, dependent both on their specific gender identity and, perhaps more importantly, on their tolerance for surgical risk. Therefore, patient choice is a significant contributor to the wide variation in masculinizing genital GCS procedures. As for developing all surgical plans, patients should be made fully aware of the surgical options and, especially, the associated risks.

The surgical interventions necessary to achieve all the above goals when fully transitioning vulvar and vaginal anatomy to penile and scrotal anatomy are listed in Figure 1; each will be considered individually along with variations in sequencing, staging, and approach. A comprehensive discussion of complications and outcomes is beyond the scope and purpose of this paper and will be mentioned only when relevant to understanding variations in surgical strategy.

\section{Hysterectomy, salpingo-oophorectomy, vaginectomy}

The removal of the uterus, ovaries, Fallopian tubes, and vagina is important to many transmasculine patients. Patients should receive counseling on options for fertility preservation; some patients may opt to delay these procedures until after they have had children ${ }^{[12]}$. The option to retain female reproductive 
organs while still creating a neophallus and/or scrotum is surgically possible but should be carefully evaluated in concert with mental health professionals who have expertise in gender-related care and know the patient well. Specifically, retention of one or both ovaries is offered at some institutions as an option for fertility preservation and/or for maintenance of bone density.

At most centers offering phalloplasty, hysterectomy is indicated whenever a patient desires to have urethral lengthening. The sequencing of hysterectomy, salpingo-oophorectomy, and vaginectomy can vary. Hysterectomy and salpingo-oophorectomy are commonly performed using a transvaginal or standard laparoscopic approach during a separate stage in advance of masculinizing genital surgical procedures ${ }^{[13]}$. A primary advantage of this staging is to avoid the longer operative times, increased procedural blood loss, and greater physiologic disturbance when combining these with other procedures ${ }^{[14]}$. Note that chest recontouring can be performed at the same time as hysterectomy and salpingo-oophorectomy.

For vaginectomy, there is variation in the specific technique used to ablate the vaginal mucosa. Although direct surgical excision may entail more blood loss, and although fulgarization may result in a higher chance of retained vaginal mucosa, at present, there appear to be limited data ${ }^{[14]}$ indicating the superiority of any one of the three commonly employed methods: fulgarization ${ }^{[15]}$, direct surgical excision ${ }^{[16]}$, or dual-approach, robotically assisted excision ${ }^{[17]}$. The selected method depends on surgeon expertise and preference and on the staging and specific method of pars fixa construction.

For patients desiring urethral lengthening, pars fixa construction with concomitant vaginectomy provides additional layers of vascularized tissue that may prevent urologic complications ${ }^{[15]}$. However, due to anecdotal reports of urinary leakage and chronic accumulation in the vaginectomy cavity, which can require complex, secondary correction, some centers opt to perform vaginectomy at the time of hysterectomy and salpingo-oophorectomy ${ }^{[17,18]}$. Still, many high-volume centers prefer to perform vaginectomy at the time of pars fixa construction to allow the use of vascularized anterior vaginal myomucosal flaps to create a portion of the pars fixa urethra, hypothesizing that this may reduce the incidence of urinary strictures and fistulas ${ }^{[15,19-21]}$. Note that although pars fixa construction has been described in patients who choose not to undergo vaginectomy, the significant risk profile for urethral complications with this approach leads most centers, current authors included, to advise against it.

\section{Tactile and erogenous sensation}

There is also variability in the specific peripheral nerves used to restore tactile sensation in the neophallus. However, restoration of cutaneous sensation in the phallus is always via straightforward nerve coaptation between a cutaneous nerve of the flap and a sensory nerve in the recipient site. This aspect of phalloplasty has been well covered in detail in two recent reviews and we will not elaborate further here ${ }^{[22-24]}$.

Despite variability in specifics to restore cutaneous sensation in the neophallus, one aspect of masculinizing genital surgery that varies little among centers is that the strategy is to preserve rather than ablate and then try to restore erogenous and orgasmic sensation. To that end, virtually all centers performing phalloplasty leave a de-epithelialized clitoris with at least one dorsal clitoral nerve intact at the base of the neophallus ${ }^{[11,25-28]}$. Although there are isolated centers that divide both clitoral nerves to reinnervate the cutaneous skin of the neophallus ${ }^{[29]}$, considerable data confirming the poor recovery of cutaneous sensation after any manner of peripheral nerve division and repair has led to the overwhelming consensus not to rely on the reinnervation of the cutaneous surface of the phallus achieving sufficient reinnervation for erogenous sensation. This consensus is also based on data demonstrating that retention of an innervated, de-epithelialized clitoris will preserve erogenous and orgasmic sensation in nearly $100 \%$ of patients undergoing masculinizing GCS ${ }^{[25,26,30]}$. 

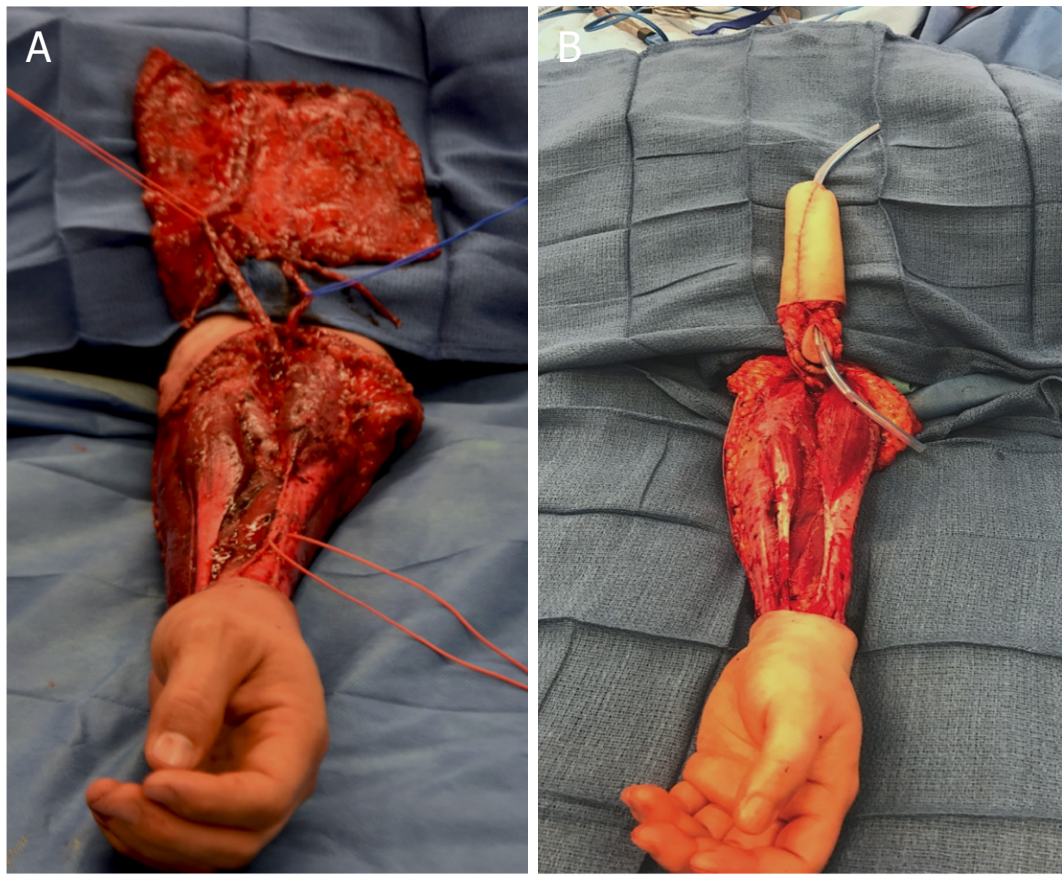

Figure 2. Radial forearm free flap (RFFF) ${ }^{[31]}$. A-B: tube-in-a-tube. The flap is then folded in to make two tubes, with epithelium lining the urethra as well as the surface of the phallus. There is a resultant large donor site defect requiring skin grafting. The RFFF is based upon the radial artery with the original flap dimensions of $10 \mathrm{~cm} \times 11-12 \mathrm{~cm}$. The length of this flap is determined in part by the length of the forearm, which will limit the length of the reconstructed phallus. Photos courtesy of Dr. Jens Berli

\section{PHALLOPLASTY}

The large cutaneous surface area of the male phallus dictates the use of a large cutaneous flap for phallic construction. In the past, random-pattern cutaneous flaps were most commonly used, but axial pedicled or microvascular free flaps dominate at present ${ }^{[29-31]}$. The free radial forearm flap (RFFF) and the anterolateral thigh pedicled or free flap (ALT) are, by a considerable margin, the most common donor site choices currently. The latissimus dorsi (LD) myocutaneous flap ${ }^{[32,33]}$ and the superficial circumflex iliac artery flap $(\mathrm{SCIP})^{[34,35]}$ are used at select centers. The free fibula osteocutaneous flap ${ }^{[35-37]}$ and the lower abdominal pedicled flap ${ }^{[29,38]}$ are used less frequently. To add to this heterogeneity, the method of penile urethra construction will influence flap choice and, at times, entail "composite phalloplasty" which is the use of two separate flaps: one for the phallus itself and a second flap for the pars pendulans urethra.

At present, the most commonly employed flap for phallic construction in transmasculine patients is the RFFF, first reported by Chang and Hwang ${ }^{[28]}$ in 1984 [Figure 2]. Advantages of the RFFF are: (1) extremely reliable vascular and peripheral neural anatomy ${ }^{[39]} ;(2)$ the forearm is thin and pliable in most individuals, allowing for simultaneous creation of the pars pendulans urethra via the "tube-in-a-tube" technique ${ }^{[28,40]}$; and (3) the RFFF having the highest innervation density of all the available flaps, providing the best potential for cutaneous reinnervation, and the ulnar, volar surface of the forearm being hair-free in many individuals, lessening or sometimes even obviating the need for hair removal prior to phalloplasty. In addition, the RFFF donor site results in no significant functional disturbance of the arm and hand for the large majority of patients ${ }^{[4]}$. The primary disadvantages of the RFFF are the large donor defect in forearm that must be skin grafted, occasional complications including edema in the hand or sensory neuromas ${ }^{[42]}$, and, if the patient's forearm is short, a limitation on phallic length [Figure 2]. Despite strategies to reduce donor site deformity ${ }^{[43]}$, some patients refuse the RFFF as they consider the forearm scar to be stigmatizing ${ }^{[44]}$. Regardless, most surgeons performing gender confirming phalloplasties consider the RFFF to be the best flap donor site at the present time. 


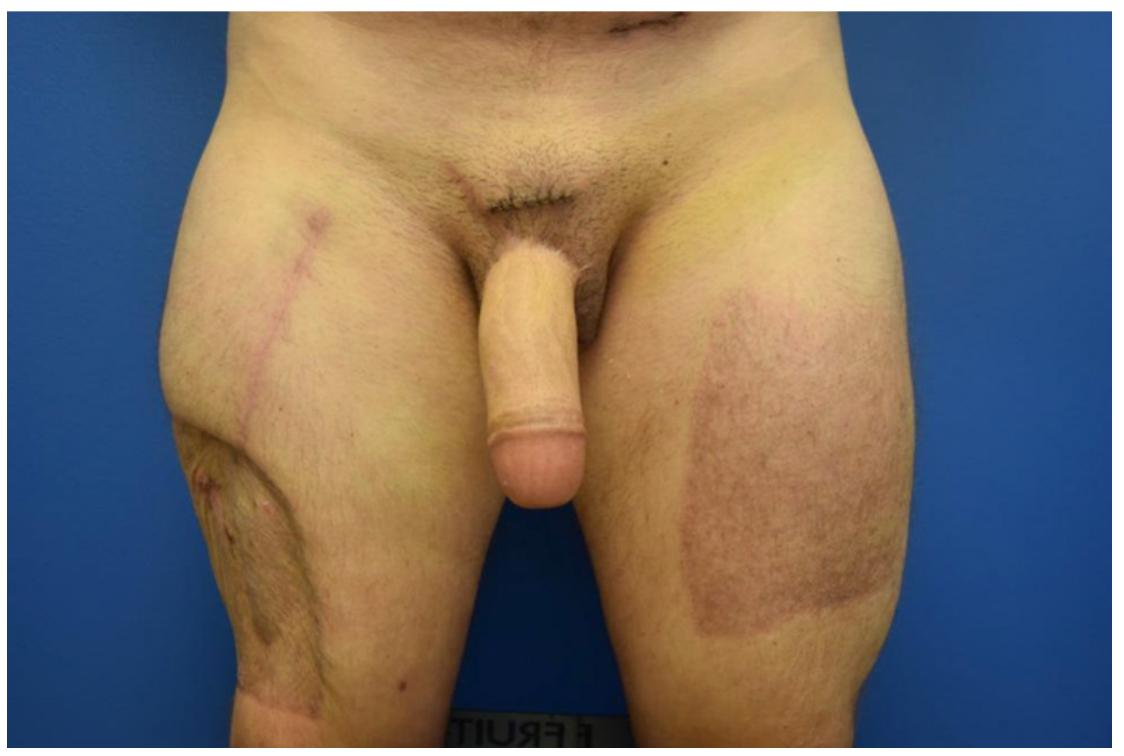

Figure 3. Anterolateral thigh flap (ALT) design. The ALT is based on the lateral femoral circumflex system ${ }^{[48]}$. The dimensions of this flap are determined by the available perforators. Generally, it should be approximately $20 \mathrm{~cm}$ in width for a tube-in-a-tube design and can vary in length. The flap should be as distal as possible to ensure pedicle length. Given the dimensions of this flap, the donor site must be skin grafted. Photos courtesy of Dr. Jens Berli

Because the donor site is easily concealed beneath clothing, the ALT flap has gained popularity for phallic construction since first reported for that purpose in 2005 [Figure 3] ${ }^{[45]}$. The ALT can often be performed as a pedicled, rather than as a microvascular, flap, avoiding the potential for complete flap failure secondary to anastomotic thrombosis. The ALT also has a very large cutaneous territory, and in very thin patients, a tube-in-a-tube technique to construct the penile urethra is possible. Although phallic length is generally not limited by the cutaneous territory of the ALT, and although patients may request this, it is generally inadvisable to create a phallus beyond the "standard" dimensions of 5-6 inches. The reason for this is that the thigh often has a thick layer of subcutaneous fat, so tubing the flap into a phallus can be difficult, increasing the chances of partial or total flap loss and sometimes resulting in an unnaturally thick and heavy, "Coke-can" penis pre-disposed to long-term mons pubis and phallic ptosis. This ptosis is difficult to remedy since subsequent debulking of the phallus jeopardizes both the vascularity and innervation of the flap. Furthermore, except in very thin patients as already noted, the bulkiness of the flap frequently precludes creating the penile urethra using the tube-in-a-tube strategy, another strategy for penile urethra construction is often necessary, resulting in additional staged procedures (see Pars Pendulans Construction below ${ }^{[46]}$. In addition, the ALT donor site must be skin grafted with a significant scar burden [Figure 3]. Lastly, the innervation density of the thigh is low and the single nerve available to restore cutaneous sensation, the lateral cutaneous nerve of the thigh, is often small and has variable anatomy limiting the return cutaneous sensation after $\mathrm{ALT}^{[47]}$. For all these reasons, the ALT is a second-choice option usually reserved for thin patients who are adamant that they cannot accept a forearm donor site. Of note, tissue expansion and liposuction of the ALT flap several months in advance of phalloplasty may both delay its vascular territory and obviate the issue with flap bulk ${ }^{[48]}$.

In considering other flaps, most, as already mentioned, are used preferentially in single centers, used infrequently, or mainly of historical interest. Djordjevic et al. ${ }^{[32]}$ have advocated phalloplasty using the latissimus dorsi myocutaneous flap. Advantages include the reliable donor site anatomy, the inconspicuous donor site that, with adjacent tissue rearrangement, can be closed primarily, and the large amount of tissue available. The authors also speculate that a reinnervated latissimus muscle can aid phallic rigidity and allow penetrative intercourse, although data to confirm this are lacking ${ }^{[32]}$. Significant disadvantages, however, 
have limited the wide use of the LD flap for phalloplasty; most significant are the inability to restore cutaneous sensation in the phallus and the need to construct a penile urethra using a second flap or staged skin grafting. The SCIP has also seen limited use for both neophallic and penile urethral construction ${ }^{[34,35]}$. Limitations in the cutaneous skin paddle size, the arc of rotation of the flap, and the difficulty in restoring cutaneous sensation have restricted its use to isolated centers ${ }^{[34,35]}$. The fibula osteoseptocutaneous flap was also conceptualized as a way to provide for penile rigidity, but its use is limited by the complex dissection necessary, the morbidity of the donor site, an insufficient cutaneous island to construct a penile urethra, and the inconvenience and complications resulting from a permanently rigid neophallus ${ }^{[36]}$.

Lastly, it should be noted that "shaft-only phalloplasty" is an option chosen by some patients ${ }^{[29]}$. By constructing only the phallus to affirm male gender, this approach avoids the multi-stage complexity and many of the risks inherent to a complete female-to-male anatomic transformation. Although any cutaneous flap large enough for phallic reconstruction can be used ${ }^{[49]}$, the ALT flap is a more common choice for flaponly phalloplasty than it is for full male genital construction. In addition, local pedicled flaps, in particular the lower abdominal "butterfly" flap, can be used since robust axial flap vascularity to support urethral construction is not necessary ${ }^{[50]}$. If a patient chooses a shaft-only phalloplasty, there are then three distinct options regarding the management of the vulva and vagina: (1) leave genital/vulvar and reproductive anatomy unchanged; (2) perform a hysterectomy, vaginectomy, scrotoplasty and perineal urostomy; or (3) perform a vaginal preservation vulvo-scrotoplasty. In this technique the vaginal canal and native urethra are preserved while the clitoris is buried and the labia majora are used to create a neo-scrotum.

Note that the considerable variation in flap choice and approach to phalloplasty exists not only between, but even within high-volume centers ${ }^{[51]}$. The major advantages and disadvantages of each flap choice described above are listed in Table 1.

\section{Glansplasty/coronaplasty}

Many patients undergoing phalloplasty will request a glansplasty (also called coronaplasty) to mimic the coronal groove and coronal ridge present in circumcised cis-males ${ }^{[52]}$. Despite minor variations, this is nearly universally done by incising the neophallus along the planned coronal groove, elevating a short distally-based flap, and either imbricating the flap back to itself or skin grafting the underside to form the coronal ridge. The proximal raw area of the coronal groove can be left to heal secondarily or skin grafted. More complex methods using diced cartilage grafts ${ }^{[53]}$, hyaluronidase injections ${ }^{[54]}$, or even two separate free flaps, one for the glans penis and one for the penile shaft ${ }^{[5]}$, have been reported as isolated case series but have not been widely adopted. Regardless of the technique used, the coronal ridge has a tendency to flatten over time and repeat coronaplasty is sometimes necessary ${ }^{[55,56]}$. In addition, there have been reports of distal flap necrosis when coronaplasty is done primarily, at the time of phallic construction ${ }^{[57]}$. For this reason, and since masculinizing genital GCS is almost always a series of staged operations, it may be advisable to perform coronaplasty as a delayed procedure, especially for the ALT where the perforators are usually situated more proximally in the flap. Lastly, tattooing can improve the appearance of the glans created by any of the methods noted above.

\section{Urethral construction}

The female urethral orifice terminates in the perineum just anterior to the vaginal introitus. Urination from the tip of a neophallus, therefore, requires construction of both the pars fixa and pars pendulans urethra. Because of both the complexity of constructing the pars fixa urethra and the reported $30 \%$ $70 \%$ rate of subsequent urethral strictures and fistulae $e^{[27,58]}$, specific expertise is required to perform these procedures and manage the complications. Therefore, in centers performing phalloplasty with full urethral reconstruction, a collaborative team that includes expertise in reconstructive microsurgery and in reconstructive urology is essential. 
Table 1. Flap selection for phalloplasty

\begin{tabular}{|c|c|c|}
\hline Staging & Advantages & Disadvantages \\
\hline Radial forearm free flap & $\begin{array}{l}\text { Phallus and pars pendula reconstruction with one flap } \\
\text { Long pedicle } \\
\text { Reliable anatomy } \\
\text { High density of nerve innervation } \\
\text { Thin flap in obese and overweight patients }\end{array}$ & $\begin{array}{l}\text { Aesthetically unpleasing donor site } \\
\text { Skin graft needed for donor site } \\
\text { Donor site sensory disturbance and neuroma possible } \\
\text { Phallus length limited by forearm length }\end{array}$ \\
\hline Anterolateral thigh flap & $\begin{array}{l}\text { Phallus and pars pendula reconstruction with one flap } \\
\text { Long pedicle } \\
\text { Flap can be pedicled } \\
\text { Easily concealable donor site }\end{array}$ & $\begin{array}{l}\text { Thick flap in overweight and obese patients } \\
\text { Skin graft needed for donor site } \\
\text { Variable perforator anatomy }\end{array}$ \\
\hline Latissimus flap & $\begin{array}{l}\text { Reliable anatomy } \\
\text { Long pedicle } \\
\text { Muscle can be reinnervated and cause "pseudo- } \\
\text { erection" } \\
\text { Concealable donor site }\end{array}$ & $\begin{array}{l}\text { No cutaneous sensation } \\
\text { Must perform pars pendula reconstruction in second } \\
\text { stage }\end{array}$ \\
\hline $\begin{array}{l}\text { Superior circumflex iliac } \\
\text { perforator flap }\end{array}$ & $\begin{array}{l}\text { Can be used as a pedicled flap } \\
\text { Minimal donor site morbidity }\end{array}$ & $\begin{array}{l}\text { Two flaps needed for phallus and pars pendula } \\
\text { reconstruction } \\
\text { Thick abdominal flaps in overweight patients } \\
\text { Limited ability to restore sensory innervation in the } \\
\text { phallic skin }\end{array}$ \\
\hline Free fibula flap & Has rigidity for sexual intercourse & $\begin{array}{l}\text { There is constant phallus rigidity } \\
\text { Short pedicle } \\
\text { Morbid donor site } \\
\text { Phallus length limited by length of fibula harvest to } \\
\text { preserve ankle mortise and fibular head }\end{array}$ \\
\hline
\end{tabular}

There are a variety of donor sites for phalloplasty, with the most common being the radial forearm free flap. There is variation based on advantages and disadvantages according to the individual patient and institution

\section{Pars fixa urethra (also referred to as the perineal urethra)}

Among centers that perform masculinizing GCS, there is a wide diversity of specific technical details for pars fixa construction. The specific techniques for pars fixa reconstruction have been reported elsewhere (see references below) and are beyond our purpose and scope here. That said, the nearly universal strategy is to use adjacent tissues, sometimes augmented with skin or buccal mucosal grafts, to construct a hairless, epithelial-lined tube from the location of the female urethral orifice to the base of the neophallus. The variations in specific techniques include (1) the degree of clitoral chordee release and resection of clitoral skin performed when repositioning the clitoral body ${ }^{[38,59-61]} ;(2)$ the timing of vaginectomy and the use (or not) of an anterior vaginal myomucosal turnover flap to augment the proximal pars fixa ${ }^{[20,21,62]}$; (3) the use (or not) of skin or buccal mucosal grafts to form the dorsal "floor" of the pars fixa ${ }^{[61-65]}$; (4) the specifics of labia minora pedicled flaps to construct the ventral "roof" of the pars fixa ${ }^{[60-65]}$; (5) the timing of pars fixa construction (discussed below); and (6) the use (or not) of a pedicled gracilis muscle or other vascularized flap to augment healing of the multiple anastomotic suture lines necessary ${ }^{[66,67]}$. These variations have been employed in virtually every combination at various centers. Most importantly, the reported urethral complication rates vary most between centers, and not between specific surgical techniques or from differences in staging. That is, no single specific technique or staging strategy has convincingly demonstrated reduced urethral complications.

\section{Pars pendulans urethra (also referred to as the penile urethra)}

Variations in reconstruction of the penile urethra are largely a function of the specific flap used to construct the neophallus. As already mentioned, an advantage of the RFFF is that it is thin and pliable with robust vascularity, allowing construction of the penile urethra at the time of free-flap phalloplasty using the tubein-a-tube technique [Figure 3] ${ }^{[28]}$. It has been hypothesized that the very large skin island necessary to do a one-stage penile urethral construction at the time of phalloplasty requires pushing the limits of the vascular territory of the RFFF and that this may account for the high rates of urethral complications; specific technical modifications may improve vascularity in the final RFFF territory ${ }^{[68]}$. Although using the ALT in a similar one-stage fashion has been described, the bulkiness of the flap precludes this approach in the majority of patients ${ }^{[69]}$. 
Two general strategies have been employed to construct the penile urethra in flaps that do not lend themselves to a primary, tube-in-a-tube pars pendulans constructions. The first is to employ two separate flaps, one for the phallus and a second flap for the penile urethra. Phallic construction using an ALT or LD flap and urethral construction at the same time using a RFFF, ulnar artery forearm flap, SCIP flap, or pedicled labia minora flaps have been described ${ }^{[69-72]}$. The principle advantages of this approach are freedom of design, lessened donor site deformity, and the robust vascularity in both flaps. The disadvantages are the morbidity of two separate donor sites and the cumulative risk of doing two separate pedicled or microvascular flaps simultaneously.

The second strategy is to perform a staged urethral fabrication using skin, vaginal mucosal, buccal mucosal or even uterine or colonic grafts ${ }^{[21,73,74]}$. This strategy has been employed in two ways. The first, mentioned for completeness sake only, is to pre-fabricate a urethra within the phalloplasty flap as an initial stage ${ }^{[73,74]}$. Skin, vaginal mucosal, and/or buccal mucosal grafts are harvested and tubed around a Foley catheter. The flap, usually the ALT or RFFF, is then partially elevated and the Foley/graft construct is implanted within the substance of the flap. After a delay of 3 or more months to allow healing and vascularization of the graft, the flap, now with the pre-fabricated urethra, is elevated for phallic construction. Another described option is to place two buried skin grafts opposing one another. This makes postoperative care and hygiene easier. At the second surgery, the posterior skin graft is left in place while the anterior one is tubularized. Despite the initial enthusiasm ${ }^{[7]}$, this approach has been largely abandoned due to high rates of complex urethral complications, especially long-segment strictures ${ }^{[7]]}$.

As an alternative, described primarily for the ALT, the phallic flap can be performed first, with construction of the pars pendulans urethra done in two subsequent stages ${ }^{[75]}$. In this approach, a flap-only ALT phalloplasty is performed without either pars fixa or pars pendulans construction. At a second stage, the phallus is split along its ventral surface and the graft material of choice, usually a skin graft, is laid into the cleft. After several months for graft healing, the penile urethra is formed by tubing the skin graft, usually with a simultaneous pars fixa construction. This strategy has the advantage of allowing full visualization of graft healing prior to tubing the penile urethra with the obvious disadvantage of necessitating a minimum of three stages to construct the penile urethra.

\section{Staging of urethral construction}

As already noted above, there is variation in the staging of both pars fixa and pars pendulans urethral construction; this accounts for the majority of the variance between centers doing masculinizing GCS. Some centers perform phallic pars fixa and pars pendulans construction in a single operation ${ }^{[19]}$. Some centers perform a pars fixa urethra construction, often along with a formal metoidioplasty as an initial step, followed by a phalloplasty with simultaneous construction of the penile urethra ${ }^{[75]}$. This sequence can also be reversed, with the phallic flap and penile urethral construction performed as a first stage, followed by pars fixa construction as a second procedure ${ }^{[75]}$.

Staging urethral construction has the obvious disadvantage of requiring more than one operation to establish urethral continuity. Advantages, however, are shortened operating times for each stage, the preservation of critical anatomy should the phallic flap fail, and, from first principle reasoning, a lessened amount of surgical swelling and inflammation at the time of pars fixa to pars pendulans urethra anastomosis. An additional advantage to staging may be improved predictability for the recovery and return to work for the patient after smaller, staged operations rather than a single, much larger procedure. It is critical to note, however, that although staging has been purported to reduce urethral complications, the variation between centers and case-series in reported rates of urethral strictures and fistulas is greater than the variation between urethral construction techniques and strategies. That is, no single technique or staging strategy has proven superior in reducing overall urethral complication rates. That said, the current 


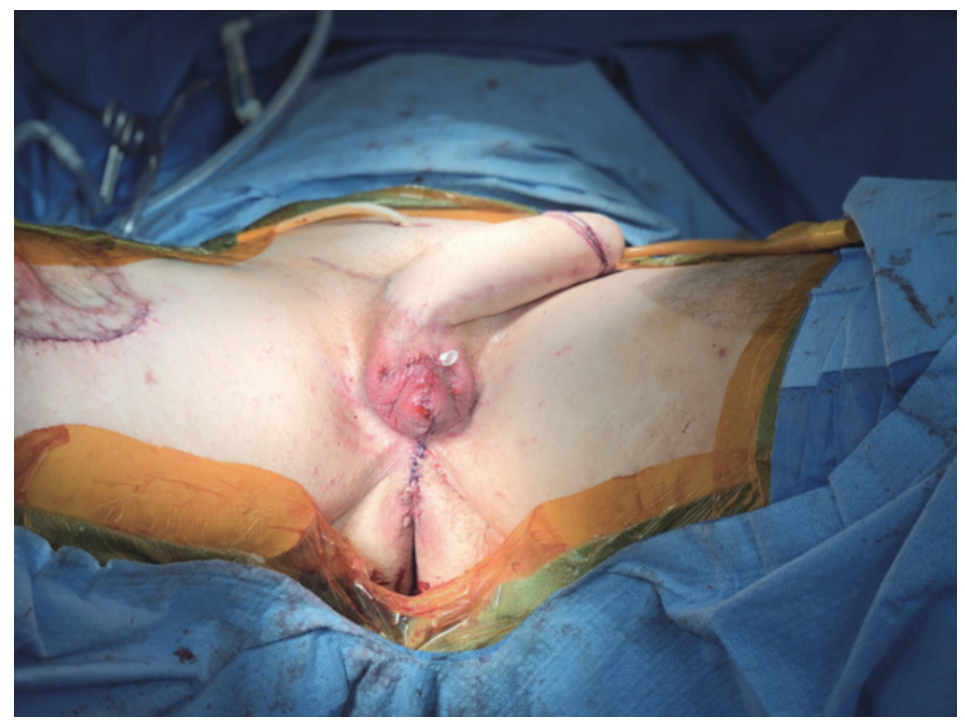

Figure 4. Status after second stage in anterolateral thigh phalloplasty (tube within a tube) with scrotoplasty. Scrotoplasty is performed using anteriorly based labia majora flaps, which are advanced to the midline. The perineum posterior to the scrotoplasty is then closed. Photo courtesy of Dr. Jens Berli

literature presents vastly heterogenous data and often lacks granular details. Complication rate as measure of superiority of procedures may fall short as it omits details on complication severity and impact on patient reported outcomes. For example, a small fistula may be amenable to a short outpatient procedure, whereas a long stricture may require a two-stage repair and longer urinary diversion. Future research should therefore also focus on complication severity and not simply on overall urethral complication rates.

\section{Scrotal construction and testicular implants}

Several specific techniques of scrotal reconstruction have been described, but all rely on a common strategy, the use of adjacent tissue flaps to form the scrotum, and following a suitable delay for healing, the placement of testicular implants ${ }^{[19]}$. Most commonly, bilateral, anteriorly based labia majora flaps are used for the skin of the scrotum [Figure 4$]^{[19]}$. The placement of testicular implants is straightforward and has been well described elsewhere ${ }^{[7]}$.

\section{Erectile prostheses}

Although a few centers use osteocutaneous flaps or place cartilage grafts primarily at the time of phallic construction $^{[21,74]}$, for most patients, the ability to achieve penile rigidity sufficient for penetrative intercourse will rely on the placement of an erectile prosthesis. Despite enthusiastic demand from some patients and short-term data indicating efficacy, considerable variation in philosophy and the technical specifics regarding erectile prostheses are driven by high rates of eventual prosthetic infection and/or extrusion and of prosthesis malfunction ${ }^{[7]}$. Analysis of existing data by some centers leads them to conclude that the risks outweigh the benefits, and they advise patients in advance that they do not recommend erectile prosthesis placement. For centers that do place prostheses, there is considerable variation in surgical specifics. A thorough review of the various types of penile prosthesis is beyond our scope, but the surgeon and patient will need to choose between the two general categories: semi-rigid or inflatable prostheses ${ }^{[77]}$. When placing inflatable prosthesis in cis-males, two cylinder devices are employed, with one cylinder placed within each corpora cavernosa. For trans-males, some centers place a single inflatable cylinder or semi-rigid element, especially for RFFF phalloplasties. Other centers may place dual-cylindered devices, especially for ALT phalloplasties, where the weight and bulk of the flap makes rigidity difficult with a single chamber ${ }^{[76]}$. In addition, attempts to reduce the extrusion rate have focused on anchoring the prosthesis to the pubis with 
Table 2. Phalloplasty: common staging strategies for construction of pars fixa and pendulans urethra

\begin{tabular}{|c|c|}
\hline Staging & Procedural sequence \\
\hline Single stage reconstruction ${ }^{[28]}$ & $\begin{array}{l}\text { Phallus and pars pendulans created from a single, "tube-in-a-tube" flap (usually RFFF), } \\
\text { simultaneous vaginectomy and pars fixa construction (specific methods vary), simultaneous } \\
\text { scrotal construction }\end{array}$ \\
\hline Two stages: pars pendulans first ${ }^{[73]}$ & $\begin{array}{l}\text { Stage one: phallic flap with pars pendulans created via "tube-in-a-tube" strategy; no disturbance } \\
\text { of female urethra or labia (i.e., a discontinuous urethra without pars fixa is created) } \\
\text { Stage two: pars fixa construction (multiple specific techniques), anastomosis to previously } \\
\text { created pars pendulans, simultaneous scrotal construction }\end{array}$ \\
\hline Two stages: pars fixa first ${ }^{[73]}$ & $\begin{array}{l}\text { Stage one: pars fixa construction, often combined with vaginectomy, sometimes as a formal } \\
\text { metoidioplasty } \\
\text { Stage two: phallic flap with pars pendulans created via "tube-in-a-tube" strategy; anastomosis } \\
\text { to previously created pars fixa urethra, simultaneous scrotal construction }\end{array}$ \\
\hline $\begin{array}{l}\text { Three stages: pars pendulans first, but } \\
\text { requiring two stages }{ }^{[73]}\end{array}$ & $\begin{array}{l}\text { Stage one: phallic construction without pars pendulans (often ALT flap), no disturbance of } \\
\text { female urethra or labia } \\
\text { Stage two: incise ventral surface of the phallus, skin graft to the ventral portion of the phallus } \\
\text { Stage three: tubularization of the grafted, ventral surface of the phallus to create pars pendulans, } \\
\text { simultaneous pars fixa construction (specific methods vary), anastomosis of pars fixa and } \\
\text { pendulans, simultaneous scrotal construction }\end{array}$ \\
\hline
\end{tabular}

Like all aspects of phalloplasty, there are countless variations in the construction and staging of the pars pendula and pars fixa. The most common permutations are presented. RFFF: radial forearm free flap; ALT: anterolateral thigh

Mitek anchors ${ }^{[77]}$ and/or encasing the prosthesis within a sleeve of acellularized dermal matrix, or other biocompatible material ${ }^{[76]}$.

\section{SUMMARY AND CONCLUSION}

The wide variation in both overall strategies and in surgical specifics between surgeons and centers underscore the complexity and difficulty of masculinizing GCS. The multiple options discussed above, along with the paucity of multicenter, prospective data to guide surgical practice, has created phalloplasty chaos, which is confusing to both surgeons and patients. When guiding a patient desiring masculinizing GCS, it is paramount that surgeons are knowledgeable of all available options and the associated advantages, disadvantages, and risks. Because constructing an algorithm encompassing the multiple variations in virtually every aspect of phalloplasty discussed above would include a dozen or more specific decision points and many dozens of specific surgical pathways, each center performing masculinizing GCS should ideally employ a consistent, local algorithm tailored to the available expertise of the participating surgeons while also allowing for appropriate patient preference. All algorithms for masculinizing GCS, however, should determine first if the patient desires standing urination and if their own profile of comorbidities would make this possible. If a patient does not desire standing urination, a shaft onlyphalloplasty is a reasonable option. If a patient does desire standing urination, institutional preferences for staging and surgical specifics come into play and should be explained to the patient to provide for appropriately informed consent. The most commonly employed combinations of the multiple options are presented in Table 2.

All that said, from our interpretation of available, data we draw the following conclusions and make the following recommendations:

(1) Data strongly support the maintenance of an innervated clitoris to preserve erogenous and orgasmic potential. We strongly advise against the division of both clitoral nerves to neurotize the neophallus.

(2) From available data and from the advantages and disadvantages of each choice discussed above, the RFFF should be considered the best current flap for phallic construction. There should be compelling reasons to use other flaps in individual patients.

(3) The most frequent and most difficult complications from masculinizing GCS arise from reconstruction of the pars fixa and pars pendulans urethra. We strongly advocate close collaboration between a reconstructive microsurgeon and a reconstructive urologist to achieve the best patient outcomes. 
(4) Although vaginectomy at the time of pars fixa urethral construction is done successfully at many centers, anecdotal reports of the colpectomy cavity becoming a urinary diverticulum should be considered when performing these procedures simultaneously.

(5) There is considerable variation among centers in reported rates of minor and major urethral complications, even those using nearly identical techniques. Most importantly, there are no data at present demonstrating that any given staging of procedures, or that any of many variations in surgical specifics for urethral construction result in consistent reductions in subsequent rates of urethral strictures or fistulas.

(6) The placement of erectile prostheses in transmasculine patients after phalloplasty will be guided by the expertise, philosophy, and outcomes of each surgical team. However, all phalloplasty patients should be informed in advance that the majority of long-term studies report high rates of infection and extrusion of erectile devices.

Despite this phalloplasty chaos, we emphasize that masculinizing genital GCS is medically necessary with well-demonstrated health benefits for properly selected patients. With an increased volume of these procedures being performed ${ }^{[78]}$, and with further research in all domains, we anticipate continual advances in this difficult and challenging area of surgery.

\section{DECLARATIONS}

\section{Authors' contributions}

Made substantial contributions to conception, design and intellectual content of this article, provided administrative, technical, and material support: Lane M, Sluiter EC, Morrison SD, Coon D, Gast KM, Berli JU, Kuzon WM

\section{Availability of data and materials}

Not applicable.

\section{Financial support and sponsorship}

None.

\section{Conflicts of interest}

All authors declared that there are no conflicts of interest.

\section{Ethical approval and consent to participate}

Not applicable.

\section{Consent for publication}

Written informed consent was obtained for publication of patient images used in this manuscript. Consent for use in publication was obtained by Dr. Berli.

\section{Copyright}

(c) The Author(s) 2020.

\section{REFERENCES}

1. van de Grift TC, Elaut E, Cerwenka SC, Cohen-Kettenis PT, De Cuypere G, et al. Effects of medical interventions on gender dysphoria and body image: a follow-up study. Psychosom Med 2017;79:815-23.

2. Wernick JA, Busa S, Matouk K, Nicholson J, Janssen A. A systematic review of the psychological benefits of gender-affirming surgery. Urol Clin North Am 2019;46:475-86.

3. Manieri C, Castellano E, Crespi C, Di Bisceglie C, Dell'aquila C, et al. Medical treatment of subjects with gender identity disorder: the experience in an italian public health center. Int J Transgend 2014;15:53-65.

4. Byne W, Bradley SJ, Coleman E, Eyler AE, Green R, et al; American psychiatric association task force on treatment of gender 
identity disorder. Report of the American psychiatric association task force on treatment of gender identity disorder. Arch Sex Behav 2012;41:759-96

5. Davy Z. The DSM-5 and the politics of diagnosing transpeople. Arch Sex Behav 2015;44:1165-76.

6. Weissler JM, Chang BL, Carney MJ, Rengifo D, Messa CA 4th, et al. Gender-affirming surgery in persons with gender dysphoria. Plast Reconstr Surg 2018;141:388-96e.

7. World Professional Association for Transgender Health. Standards of care for transsexual, transgender, and gender nonconforming people. Int J Transgend 2012;13:165-232.

8. Riggs DW, Pearce R, Pfeffer CA, Hines S, White F, et al. Transnormativity in the psy disciplines: constructing pathology in the diagnostic and statistical manual of mental disorders and standards of care. Am Psychol 2019;74:912-24.

9. Budge SL. Psychotherapists as gatekeepers: an evidence-based case study highlighting the role and process of letter writing for transgender clients. Psychotherapy (Chic) 2015;52:287-97.

10. Puckett JA, Cleary P, Rossman K, Newcomb ME, Mustanski B. Barriers to gender-affirming care for transgender and gender nonconforming individuals. Sex Res Social Policy 2018;15:48-59.

11. Selvaggi G, Monstrey S, Ceulemans P, T'Sjoen G, De Cuypere G, et al. Genital sensitivity after sex reassignment surgery in transsexual patients. Ann Plast Surg 2007;58:427-33.

12. Abern L, Maguire K. Fertility preservation among transgender individuals. Fertil Steril 2018;110:e281.

13. Jeftovic M, Stojanovic B, Bizic M, Stanojevic D, Kisic J, et al. Hysterectomy with bilateral salpingo-oophorectomy in female-to-male gender affirmation surgery: comparison of two methods. Biomed Res Int 2018;2018:3472471.

14. Hougen HY, Dugi DD 3rd, Berli JU, Sajadi KP. Outcomes of transperineal gender-affirming vaginectomy and colpocleisis. Female Pelvic Med Reconstr Surg 2020; doi: 10.1097/SPV.0000000000000843.

15. Massie JP, Morrison SD, Wilson SC, Crane CN, Chen ML. Phalloplasty with urethral lengthening: addition of a vascularized bulbospongiosus flap from vaginectomy reduces postoperative urethral complications. Plast Reconstr Surg 2017;140:551-8e.

16. Nikkels C, van Trotsenburg M, Huirne J, Bouman MB, de Leeuw R, et al. Vaginal colpectomy in transgender men: a retrospective cohort study on surgical procedure and outcomes. J Sex Med 2019;16:924-33.

17. Groenman F, Nikkels C, Huirne J, van Trotsenburg M, Trum H. Robot-assisted laparoscopic colpectomy in female-to-male transgender patients; technique and outcomes of a prospective cohort study. Surg Endosc 2017;31:3363-9.

18. Dy GW, Sun J, Granieri MA, Zhao LC. Reconstructive management pearls for the transgender patient. Curr Urol Rep 2018;19:36.

19. Chen ML, Safa B. Single-stage phalloplasty. Urol Clin North Am 2019;46:567-80.

20. Zhang YF, Liu CY, Qu CY, Lu LX, Liu AT, et al. Is vaginal mucosal graft the excellent substitute material for urethral reconstruction in female-to-male transsexuals? World J Urol 2015;33:2115-23.

21. Medina CA, Fein LA, Salgado CJ. Total vaginectomy and urethral lengthening at time of neourethral prelamination in transgender men. Int Urogynecol J 2018;29:1463-8.

22. Morrison SD, Massie JP, Dellon AL. Genital sensibility in the neophallus: getting a sense of the current literature and techniques. J Reconstr Microsurg 2019;35:129-37.

23. Safa B, Lin WC, Salim AM, Deschamps-Braly JC, Poh MM. Current concepts in masculinizing gender surgery. Plast Reconstr Surg 2019;143:857-71e

24. Hadj-Moussa M, Agarwal S, Ohl DA, Kuzon WM Jr. Masculinizing genital gender confirmation surgery. Sex Med Rev 2019;7:141-55.

25. Vukadinovic V, Stojanovic B, Majstorovic M, Milosevic A. The role of clitoral anatomy in female to male sex reassignment surgery. ScientificWorldJournal 2014;2014:437378.

26. Morrison SD, Shakir A, Vyas KS, Kirby J, Crane CN, et al. Phalloplasty: a review of techniques and outcomes. Plast Reconstr Surg 2016;138:594-615.

27. Monstrey S, Hoebeke P, Selvaggi G, Ceulemans P, Van Landuyt K, et al. Penile reconstruction: is the radial forearm flap really the standard technique? Plast Reconstr Surg 2009;124:510-8.

28. Chang TS, Hwang WY. Forearm flap in one-stage reconstruction of the penis. Plast Reconstr Surg 1984;74:251-8.

29. Garcia MM, Christopher NA, De Luca F, Spilotros M, Ralph DJ. Overall satisfaction, sexual function, and the durability of neophallus dimensions following staged female to male genital gender confirming surgery: the Institute of Urology, London U.K. experience. Transl Androl Urol 2014;3:156-62.

30. Frey JD, Poudrier G, Chiodo MV, Hazen A. A systematic review of metoidioplasty and radial forearm flap phalloplasty in female-to-male transgender genital reconstruction: is the "ideal" neophallus an achievable goal? Plast Reconstr Surg Glob Open 2016;4:e1131.

31. Heston AL, Esmonde NO, Dugi DD 3rd, Berli JU. Phalloplasty: techniques and outcomes. Transl Androl Urol 2019;8:254-65.

32. Djordjevic ML, Bencic M, Kojovic V, Stojanovic B, Bizic M, et al. Musculocutaneous latissimus dorsi flap for phalloplasty in female to male gender affirmation surgery. World J Urol 2019;37:631-7.

33. Vesely J, Hyza P, Ranno R, Cigna E, Monni N, et al. New technique of total phalloplasty with reinnervated latissimus dorsi myocutaneous free flap in female-to-male transsexuals. Ann Plast Surg 2007;58:544-50.

34. Veerman H, de Rooij FPW, Al-Tamimi M, Ronkes BL, Mullender MG, et al. Functional outcomes and urological complications after genital gender affirming surgery with urethral lengthening in transgender men. J Urol 2020;204:104-9.

35. Koshima I, Nanba Y, Nagai A, Nakatsuka M, Sato T, et al. Penile reconstruction with bilateral superficial circumflex iliac artery perforator (SCIP) flaps. J Reconstr Microsurg 2006;22:137-42.

36. Sengezer M, Oztürk S, Deveci M, Odabaşi Z. Long-term follow-up of total penile reconstruction with sensate osteocutaneous free fibula flap in 18 biological male patients. Plast Reconstr Surg 2004;114:439-50; discussion 451-2. 
37. Mcroberts JW, Sadove RC. Penile reconstruction with a free sensate osteocutaneous fibula flap in the surgical management of the intersex patient. In: Zderic SA, Canning DA, Carr MC, Snyder HM, editors. Pediatric gender assignment. Boston: Springer US; 2002. pp. 283-8.

38. Dabernig J. Pedicled pubic phalloplasty in females with gender dysphoria. BJU Int 2005;96:1422-3.

39. Djordjevic ML. Novel surgical techniques in female to male gender confirming surgery. Transl Androl Urol 2018;7:628-38.

40. Colebunders B, Brondeel S, D’Arpa S, Hoebeke P, Monstrey S. An update on the surgical treatment for transgender patients. Sex Med Rev 2017;5:103-9.

41. Selvaggi G, Monstrey S, Hoebeke P, Ceulemans P, Van Landuyt K, et al. Donor-site morbidity of the radial forearm free flap after 125 phalloplasties in gender identity disorder. Plast Reconstr Surg 2006;118:1171-7.

42. Kovar A, Choi S, Iorio ML. Donor site morbidity in phalloplasty reconstructions: outcomes of the radial forearm free flap. Plast Reconstr Surg Glob Open 2019;7:e2442.

43. Garaffa G, Christopher NA, Ralph DJ. Total phallic reconstruction in female-to-male transsexuals. Eur Urol 2010;57:715-22.

44. Tran BNN, Epstein S, Singhal D, Lee BT, Tobias AM, et al. Gender affirmation surgery: a synopsis using American College of Surgeons National Surgery Quality Improvement Program and National Inpatient Sample databases. Ann Plast Surg 2018;80:S229-35.

45. Felici N, Felici A. A new phalloplasty technique: the free anterolateral thigh flap phalloplasty. J Plast Reconstr Aesthet Surg 2006;59:153-7.

46. Xu KY, Watt AJ. The pedicled anterolateral thigh phalloplasty. Clin Plast Surg 2018;45:399-406.

47. Mardini S, Chim H, Wei FC. Anterolateral and anteromedial thigh flaps. In: Wei FC, Mardini S, editors. Flaps and reconstructive surgery. 2nd ed. Elsevier; 2016. pp. 700-16.e5.

48. D’Arpa S, Colebunders B, Stillaert F, Monstrey S. Pre-expanded anterolateral thigh perforator flap for phalloplasty. Clin Plast Surg 2017;44:129-41.

49. Esmonde N, Bluebond-Langner R, Berli JU. Phalloplasty flap-related complication. Clin Plast Surg 2018;45:415-24.

50. Bajpai M. "Bird-Wing" abdominal phalloplasty: a novel surgical technique for penile reconstruction. J Indian Assoc Pediatr Surg 2013;18:49-52.

51. Hage J, Bouman F, de Graaf F, Bloem J. Construction of the neophallus in female-to-male transsexuals: the Amsterdam experience. J Urol 1993;149:1463-8.

52. Hage JJ, Bout CA, Bloem JJ, Megens JA. Phalloplasty in female-to-male transsexuals: what do our patients ask for? Ann Plast Surg 1993;30:323-6.

53. Ma S, Cheng K, Liu Y, Chen F. A new surgical procedure for penile reconstruction by combined free radial forearm flap and dorsalis pedis flap. Urology 2016;97:232-7.

54. Moon DG, Kwak TI, Cho HY, Bae JH, Park HS, et al. Augmentation of glans penis using injectable hyaluronic acid gel. Int J Impot Res 2003;15:456-60.

55. Sommeling CE, De Wolf EJ, Salim A, Monstrey S, Opsomer D, et al. A new technique for coronaplasty in penile reconstruction. J Sex Med 2018;15:920-3.

56. Besteiro J, Caterina R, Ishida L, Aki F. Microsurgical phalloplasty. J Reconstr Microsurg 2006;22.

57. Dubin BJ, Sato RM, Laub DR. Results of phalloplasty. Plast Reconstr Surg 1979;64:163-70.

58. Al-Tamimi M, Pigot GL, van der Sluis WB, van de Grift TC, Mullender MG, et al. Colpectomy significantly reduces the risk of urethral fistula formation after urethral lengthening in transgender men undergoing genital gender affirming surgery. J Urol 2018;200:1315-22.

59. Selvaggi G, Bellringer J. Gender reassignment surgery: an overview. Nat Rev Urol 2011;8:274-82.

60. Djordjevic ML, Bizic M, Stanojevic D, Bumbasirevic M, Kojovic V, et al. Urethral lengthening in metoidioplasty (female-to-male sex reassignment surgery) by combined buccal mucosa graft and labia minora flap. Urology 2009;74:349-53.

61. Djordjevic ML, Bizic MR. Comparison of two different methods for urethral lengthening in female to male (metoidioplasty) surgery. J Sex Med 2013;10:1431-8.

62. Chen ML, Reyblat P, Poh MM, Chi AC. Overview of surgical techniques in gender-affirming genital surgery. Transl Androl Urol 2019;8:191-208.

63. Wilson SC, Stranix JT, Khurana K, Morrison SD, Levine JP, et al. Fasciocutaneous flap reinforcement of ventral onlay buccal mucosa grafts enables neophallus revision urethroplasty. Ther Adv Urol 2016;8:331-7.

64. Chauhan A, Sham E, Chee J. Microsurgical urethroplasty for complex bulbar urethral strictures using the radial forearm free flap prelaminated with buccal mucosa. J Reconstr Microsurg 2016;32:378-85.

65. Hage JJ. Metaidoioplasty: an alternative phalloplasty technique in transsexuals. Plast Reconstr Surg 1996;97:161-7.

66. Kim SK, Moon JB, Heo J, Kwon YS, Lee KC. A new method of urethroplasty for prevention of fistula in female-to-male gender reassignment surgery. Ann Plast Surg 2010;64:759-64.

67. Cohen O, Stranix JT, Zhao L, Levine J, Bluebond-Langner R. Use of a split pedicled gracilis muscle flap in robotically assisted vaginectomy and urethral lengthening for phalloplasty: a novel technique for female-to-male genital reconstruction. Plast Reconstr Surg 2020;145:1512-5.

68. Safa B. "Phalloplasty." Presented for American Society of Plastic Surgeons. Virtual Grand Rounds. April 2020. Available from: https:// ednet.plasticsurgery.org/diweb/catalog/item/id/5085154/pid/5037869. [Last accessed on 17 Sep 2020]

69. Morrison SD, Son J, Song J, Berger A, Kirby J, et al. Modification of the tube-in-tube pedicled anterolateral thigh flap for total phalloplasty: the mushroom flap. Ann Plast Surg 2014;72 Suppl 1:S22-6.

70. Al-Tamimi M, Pigot GL, Ronkes B, de Haseth KB, van de Grift TC, et al. The first experience of using the pedicled labia minora flap for urethral lengthening in transgender men undergoing anterolateral thigh and superficial circumflex iliac artery perforator flap phalloplasty: 
a multicenter study on clinical outcomes. Urology 2020;138:179-87.

71. van der Sluis WB, Smit JM, Pigot GLS, Buncamper ME, Winters HAH, et al. Double flap phalloplasty in transgender men: surgical technique and outcome of pedicled anterolateral thigh flap phalloplasty combined with radial forearm free flap urethral reconstruction. Microsurgery 2017;37:917-23.

72. D'Arpa S, Claes K, Lumen N, Oieni S, Hoebeke P, et al. Urethral reconstruction in anterolateral thigh flap phalloplasty: a 93-case experience. Plast Reconstr Surg 2019;143:382-92e.

73. Liu CY, Wei ZR, Jiang H, Zhao YZ, Zhang YF. Preconstruction of the pars pendulans urethrae for phalloplasty with digestive mucosa using a prefabricated anterolateral thigh flap in a one-arm patient. Plast Reconstr Surg Glob Open 2013;1:e53.

74. Salgado CJ, Fein LA, Chim J, Medina CA, Demaso S, et al. Prelamination of neourethra with uterine mucosa in radial forearm osteocutaneous free flap phalloplasty in the female-to-male transgender patient. Case Rep Urol 2016;2016:8742531.

75. Danker S, Esmonde N, Berli JU. “Staging” in Phalloplasty. Urol Clin North Am 2019;46:581-90.

76. Kang A, Aizen JM, Cohen AJ, Bales GT, Pariser JJ. Techniques and considerations of prosthetic surgery after phalloplasty in the transgender male. Transl Androl Urol 2019;8:273-82.

77. Kocjancic E, Iacovelli V. Penile prostheses. Clin Plast Surg 2018;45:407-14.

78. Lane M, Ives GC, Sluiter EC, Waljee JF, Yao TH, et al. Trends in gender-affirming surgery in insured patients in the United States. Plast Reconstr Surg Glob Open 2018;6:e1738. 